\title{
Um Exemplo Nacional para a Produção de Fibras Lyocell ${ }^{\mathrm{i}}$
}

Ana Marta Antunes*

Mihaela Santos

Samuel Peres

Maria José Lourenço

\begin{abstract}
A Portuguese Case on the Way to Lyocell Fibers Production. Cellulosic pulp production is meant for paper but also for seminatural regenerated cellulose fibers production. In fact, the company Caima - Indústria de Celulose, S.A., in Portugal, produces cellulosic dissolved pulp with that purpose. In this work, part of Caima's dissolved pulp evaluation for Lyocell fibers production is shown, with emphasis on this material attributes. The connection between this regenerated fiber production technology, the present concept of fashion and the sustainability cycles are indicated. The most important technological parameters of a dissolved pulp for Lyocell are pointed out as well as the experimental progress from dope to fibers production.
\end{abstract}

\begin{abstract}
A produção de pasta de celulose não se destina apenas à produção de papel, e, em Portugal, a Caima - Indústria de Celulose, S.A. produz pasta solúvel adequada à produção de fibras seminaturais de celulose regenerada. Neste trabalho, apresenta-se parte da avaliação da pasta solúvel da Caima para produção de fibras Lyocell e realçam-se as características vantajosas deste material. Relaciona-se a tecnologia de produção desta fibra regenerada com o conceito atual de moda e com os ciclos de sustentabilidade. Evidenciam-se os parâmetros tecnológicos cruciais numa pasta solúvel para Lyocell e a sua evolução experimental desde a obtenção do xarope até à formação destas fibras.
\end{abstract}

\section{A pasta celulósica solúvel}

O interesse nos materiais celulósicos tem aumentado nos últimos anos devido ao facto da celulose ser um recurso renovável disponível em quantidades consideráveis. Mas é um engano comum pensar-se que a pasta de celulose se destina apenas à produção de papel. De facto, a partir de várias espécies de fibras vegetais é possível obter a denominada pasta celulósica solúvel com características específicas e adequadas à produção de fibras seminaturais de celulose regenerada. Com estas, produtos como a viscose, o modal, o cupro, as fibras de acetato e o Lyocell, conduzem a uma vasta gama de aplicações nas indústrias têxtil, automóvel, alimentar, entre muitas outras.

Graças ao franco crescimento da indústria têxtil nos últimos anos, prevê-se um aumento de aproximadamente $84 \%$ na produção global de fibras têxteis entre 2010 e 2030 (de 72,5 milhões de toneladas em 2010 para 133,5 milhões de toneladas em 2030) [1]. Deste modo, é esperado que a produção global de pasta celulósica solúvel continue a crescer, verificando-se que mais de $90 \%$ da pasta produzida mundialmente é pasta de madeira.

Em Portugal, a empresa Caima - Indústria de Celulose, S.A. produz pasta solúvel a partir da madeira da espécie Eucalyptus globulus, utilizando uma tecnologia de cozimento ao sulfito ácido seguido de uma sequência de branqueamento totalmente livre de cloro (TCF - Totally Chlorine Free) [2]. 


\section{A importância do processo produtivo}

A matéria-prima utilizada é bastante relevante na produção de pasta solúvel, tanto nos setores socioeconómico e ambiental como a nível da influência das próprias características intrínsecas a cada espécie. Não obstante, também o processo produtivo é muitíssimo importante, apresentando o processo de cozimento ao sulfito inúmeras vantagens na produção de pasta solúvel e também de alguns subprodutos, graças à elevada flexibilidade das várias etapas do processo produtivo.

A nível internacional, nomeadamente na Europa, a generalidade das fábricas de pasta celulósica química não utiliza o processo do bissulfito de magnésio (denominado por cozimento ao sulfito), mas sim o processo kraft (cozimento ao sulfato). De facto, em Portugal apenas a Caima usa o processo de cozimento ao sulfito. Estes dois processos são diferentes e têm como objetivo a obtenção de pastas com propriedades distintas. $\mathrm{Na}$ produção de pasta de papel, as características mais importantes são a brancura e outras que conferem ao papel determinadas propriedades físico-mecânicas, como a resistência. Para tal, no processo kraft são retirados a lenhina e os extratáveis da madeira procurando preservar ao máximo a celulose e as hemiceluloses. No entanto, este tipo de cozimento dá origem a pastas relativamente mais escuras, o que implica um maior consumo de agentes de branqueamento. Por seu lado, com a utilização do cozimento ao sulfito, procura-se obter na pasta solúvel características como elevados níveis de $\alpha$-celulose e teores de cinzas e cálcio muito baixos, por exemplo. Estas são características químicas importantes para a produção de determinado tipo de fibras de celulose regenerada como a viscose (atualmente o principal mercado da pasta produzida pela Caima) e o Lyocell. De salientar que estas pastas têm também um grau de brancura muito superior àquele que se obtém com o processo kraft.

\section{Processo produtivo da Caima}

A pasta celulósica solúvel da Caima é produzida a partir de madeira proveniente de florestas certificadas. Na primeira etapa de transformação química, as aparas de madeira são submetidas a um cozimento com bissulfito de magnésio $\left(\mathrm{Mg}\left(\mathrm{HSO}_{3}\right)_{2}\right)$, em condições de temperatura e pressão elevadas. Durante este processo, dissolve-se a maior parte da lenhina, ocorre a fragmentação da celulose em cadeias mais pequenas e a remoção de parte das hemiceluloses. Posteriormente, a pasta dita "crua", ou seja não branqueada, segue para a etapa de lavagem e, em seguida, para a etapa de branqueamento. Nesta fase, a pasta é tratada em três estágios consecutivos com agentes químicos para aumentar a sua brancura, eliminar o máximo de lenhina residual e de outras impurezas cromóforas e reduzir a sua viscosidade. As operações de secagem e embalamento finalizam este processo, cujas etapas principais se esquematizam na Figura 1.
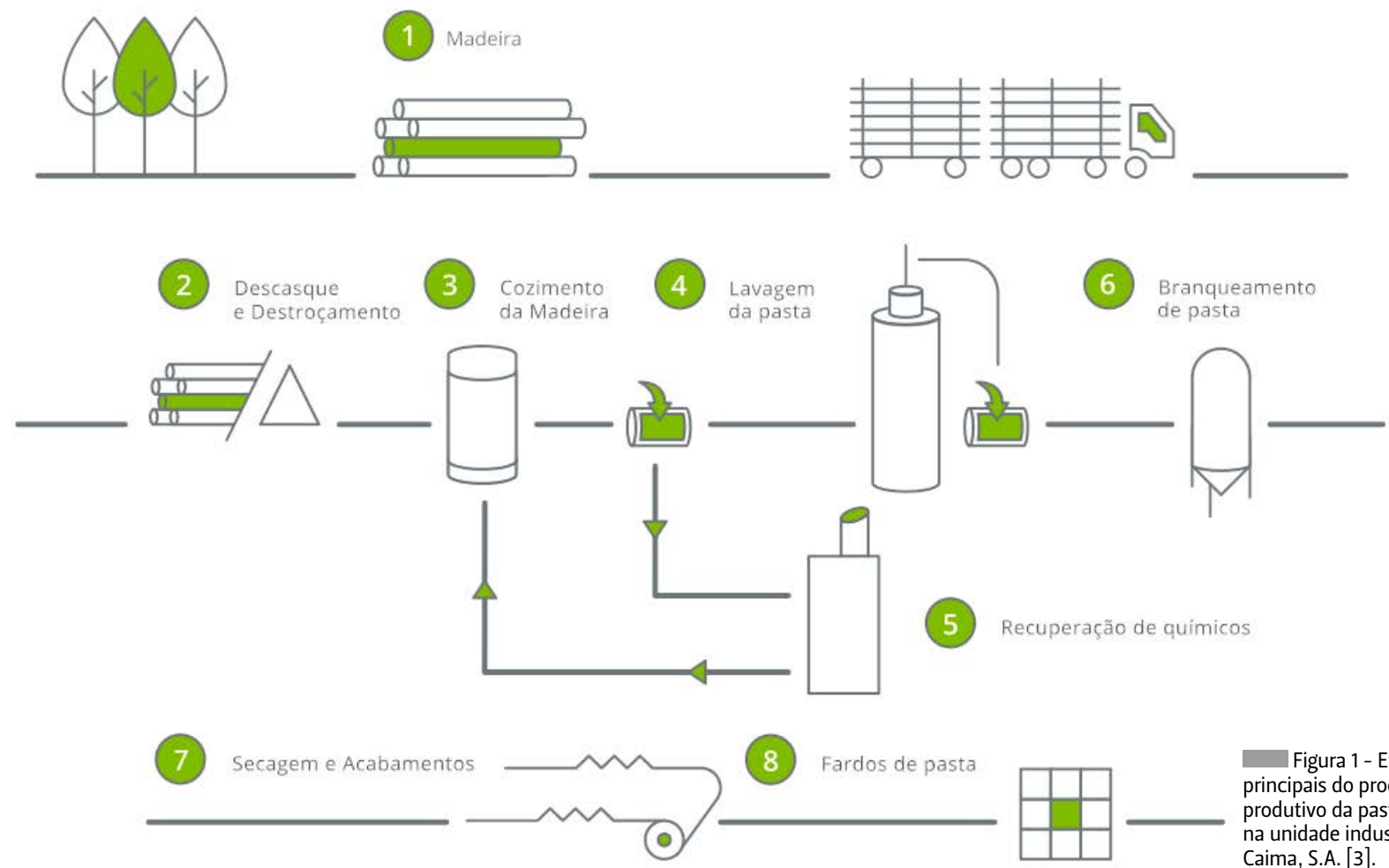


\section{O tempo presente e o que se segue...}

As possibilidades de expandir a produção de fibras naturais de algodão são, à escala internacional, cada vez mais baixas, uma vez que a área de terreno fértil sofre uma contínua redução devido à erosão e à urbanização.

Por outro lado, a Caima, S.A., estando inserida no grupo Altri, SGPS, S.A., o qual também integra a Altri Florestal, S.A., certificada pelos principais sistemas de gestão florestal, garante o cultivo sustentável do Eucalyptus globulus, matéria-prima desta indústria.

Por estas razões, e tendo em consideração a longevidade e estruturação do processo de cozimento ao sulfito, as vantagens ambientais de um processo TCF e a situação socioeconómica da Caima na região geográfica onde se encontra, a utilização da pasta solúvel que ali se produz pode e deve ser revitalizada de forma a aproveitar e criar novas oportunidades de produção e aplicação de novas fibras de celulose regenerada no mercado internacional e, ainda de modo mais premente, no mercado nacional.

Perante o processo viscose que está a jusante do fornecimento da maior percentagem da pasta solúvel da Caima, processo este que envolve direta e indiretamente uma série de etapas que constituem graves riscos ambientais e que exigem, por isso, variadíssimas intervenções e tratamentos levados a cabo por meio de recursos complexos e dispendiosos, é crucial adequar esta pasta solúvel à produção de Lyocell de forma a minimizar aqueles impactos.

\section{Lyocell}

Uma das novas fibras de celulose regenerada que tem registado elevado crescimento no mercado global nos últimos anos é, efetivamente, a fibra Lyocell. De acordo com Herbert Sixta da Universidade de Aalto, Finlândia, a comercialização das fibras Tencel ${ }^{\circledR}$ da Lenzing AG (um dos maiores produtores mundiais de Lyocell, com sede na Áustria) tem aumentado nos últimos 30 anos, conforme se mostra na Figura 2.

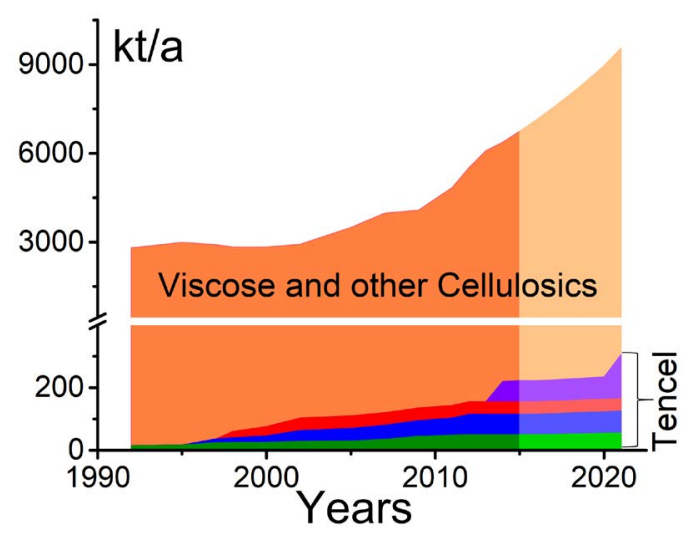

Figura 2 - Crescimento de produção de fibras Tencel ${ }^{\circledR}$ entre 1990 e 2020. Reproduzido com permissão a partir da referência [4].
As propriedades do Lyocell enquanto fibra, a sua diversidade de aplicação técnica a tecidos e a não-tecidos e o tipo de processo que lhe dá origem, baseado numa tecnologia considerada a mais sustentável na produção de fibras celulósicas e ainda com potencial para muito desenvolvimento pelos diferentes solventes que podem ser utilizados, faz com que esta hipótese de mercado seja muito desejada.

É de realçar que Lyocell é o nome genérico dado tanto ao tecido como à fibra de celulose regenerada obtida por dissolução de pasta solúvel de madeira num solvente orgânico. Da mesma forma, Lyocell é o termo que designa o processo de extrusão desta fibra que envolve uma tecnologia ambientalmente favorável que inclui produtos químicos com níveis de toxicidade muito baixos e em que as emissões de poluentes e o consumo de água são substancialmente reduzidos, em particular quando comparado com o processo viscose.

As fibras de celulose regenerada de Lyocell são de celulose II como as de viscose, mas distinguem-se por possuírem elevada cristalinidade (cristalites longas formadas devido a um arranjo molecular irregular que ocorre nas fases de extrusão e de coagulação), elevado grau de orientação, zonas amorfas bem orientadas e um grau de polimerização médio superior. Este tipo de morfologia origina, comparativamente à viscose, uma resistência à tração e uma tenacidade mais elevadas em estado seco e húmido, um módulo de deformação também maior e um grau de encolhimento, após lavagem e secagem, inferior (mesmo relativamente ao algodão).

O Lyocell tem uma grande versatilidade, podendo ser usado tanto em produtos têxteis, incluindo colchões e vestuário, como em não-têxteis, incluindo filtros, fraldas, cotonetes e produtos cirúrgicos.

\section{Da tecnologia à moda - um ciclo de sustentabilidade}

A maior sustentabilidade do Lyocell é inegável, não apenas pelas vantagens que apresenta a nível de tecnologia de processo e de solventes utilizados, como também pela excelente oportunidade de um ciclo de vida fechado, dada a sua elevada qualidade, viabilidade de reutilização e possibilidade para ser 100\% biodegradável. Note-se que o conceito de sustentabilidade e a garantia dos princípios de equilíbrio ecológico entre atividades económicas e industriais é um dos maiores desafios que se tem de enfrentar.

A fibra de Lyocell, suave, absorvente, resistente, respirável, antirrugas, fluída, de manutenção simples e ainda biodegradável, foi a primeira fibra de celulose regenerada aprovada pela FTC - Federal Trade Commission, em 1996 (FTC Approves "Lyocell" for Use in Fabric Content Labeling, FTC Matter No. P928401, April 12, 1996; Federal Trade Commission). 
A moda é um mecanismo rápido, passageiro e insaciável de novidade. Ao longo da história, os têxteis têm estado intimamente relacionados com a inovação científica e tecnológica. Atualmente, as novas exigências sociais e a evolução tecnológica permitem gerar ideias e materiais nunca antes imaginados. Defende-se que o vestuário deve ser transformado na expressão de um estilo de vida cuidadoso e de uma personalidade onde coexistem preocupações com o ambiente e com a individualidade, a realização de desejos e as necessidades humanas. Assim, existe uma prioridade na investigação de soluções para novas bases têxteis que correspondam às exigências de funcionalidade e estética, e sustentabilidade, quer do consumidor quer do designer de moda. Também é importante realçar o carácter sustentável de novas bases têxteis, desmistificando o carácter ecológico de algumas fibras naturais, como o algodão, "material maravilhoso!" mas que tem um grande impacto ambiental.

0 Lyocell pode ter texturas diferentes, mas o tecido básico é macio ao toque, hipoalergénico e $50 \%$ mais absorvente do que o algodão. Todas as características desta fibra e deste tecido, mas muito especialmente a sua "amabilidade" para a pele, constituem as principais vantagens que o Lyocell oferece em relação a muitas outras alternativas.

Na moda, as etiquetas "100\% Lyocell" são visíveis principalmente no atletismo e em peças de guarda-roupa feitas para durar. A roupa com esta fibra pode ser enrolada e colocada na mala. Não amarrota e também não se suja facilmente [5]. Portugal fabrica roupa com tecido Lyocell há já algum tempo (Figura 3) apesar de esta importação ser bastante dispendiosa, 0 que dificulta a sua aquisição no nosso país. Estaremos a caminho deste investimento nacional?

Figura 3 - Etiqueta "100\% Lyocell" de uma peça de vestuário fabricada em Portugal.

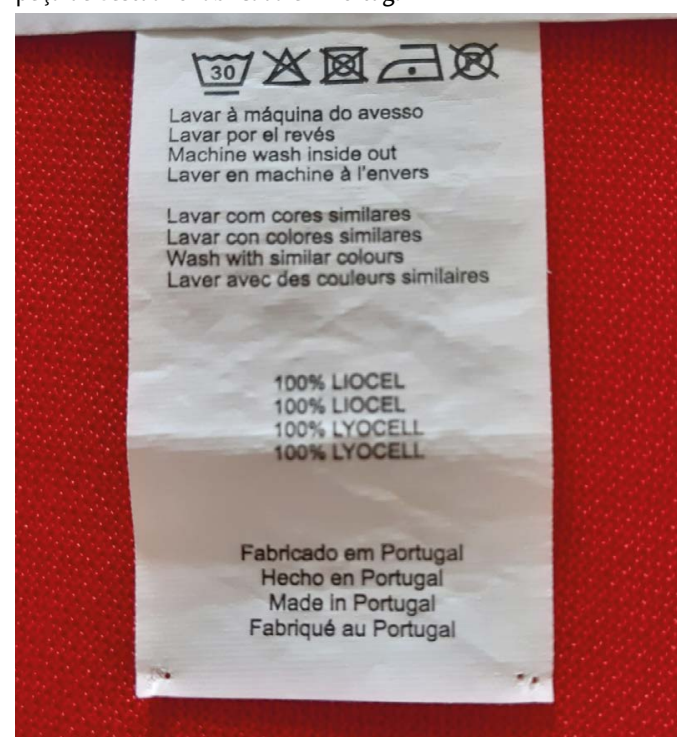

\section{Dissolução de celulose}

O processo Lyocell tornou-se possível no seguimento de muita investigação no sentido de descobrir um solvente apropriado à dissolução direta da celulose, sem necessidade de derivatização. Efetivamente, o comprimento relativamente elevado das cadeias de celulose e o seu empacotamento compacto devido à presença de numerosas ligaç̃ões por pontes de hidrogénio, tornam este biopolímero (Figura 4) muito difícil de dissolver. Por esta razão, processos como o da viscose incluem uma etapa de derivatização, na qual se forma logo de início um polímero intermediário derivado da celulose (xantato de celulose), de dissolução mais fácil e que permite a regeneração da celulose.

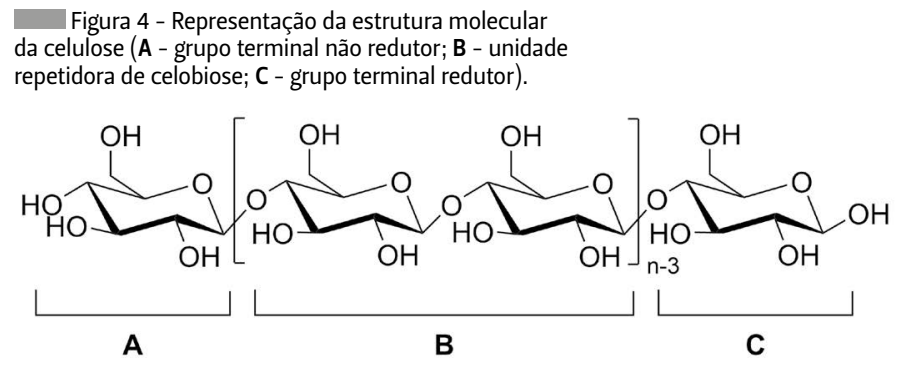

Assim, o desenvolvimento de solventes que dissolvam a celulose sem a necessidade de formação de derivados intermediários, que sejam de baixo custo e ambientalmente favoráveis, é essencial para o sucesso da utilização sustentável da celulose como componente de materiais poliméricos. Com efeito, têm sido encontradas algumas alternativas de solventes não-derivatizantes com os quais os produtos de celulose regenerada podem ser preparados diretamente a partir de uma solução de celulose via dissolução física. Os líquidos iónicos e as soluções alcalinas de ureia e hidróxido de sódio são alguns exemplos. Mas o primeiro a ser utilizado e mais comercializado é um óxido de amina terciária, o $\mathrm{N}$-óxido de $\mathrm{N}$-metilmorfolina (NMO, N-Methylmorpholine N-oxide), cuja estrutura se apresenta na Figura 5.<smiles>CN1CCOCC1</smiles>

Figura 5 - Estrutura do $N$-óxido de $\mathrm{N}$-metilmorfolina (NMO).

Apesar de se tratar de um processo simples comparativamente ao processo viscose, a formação de um xarope (dope) de Lyocell homogéneo é o passo crítico e mais sensível de todo o mecanismo. A formação da solução de celulose em sistema aquoso de NMO começa com a preparação de uma polpa (slurry) em que ocorre 
simultaneamente o intumescimento (swelling) e o cisalhamento da pasta. Neste passo, o NMO aquoso penetra nas regiões intra- e intercristalinas das fibras da pasta, quebrando as ligacções por pontes de hidrogénio existentes. 0 cisalhamento garante uma distribuição uniforme do NMO através do material, formando-se uma polpa uniforme que é o ponto de partida para o processo de dissolução da celulose. No passo da dissolução, sob vácuo e a temperatura elevada, dá-se em simultâneo a dissolução propriamente dita da celulose em NMO e a evaporação do excesso de água. É nesta fase que o NMO destrói a estrutura cristalina da celulose e se forma uma solução de celulose homogénea - o xarope.

Em termos gerais, quando as fibras de celulose são inicialmente colocadas num agente de intumescimento ou num solvente, sob condições processuais específicas, pode ocorrer um processo de swelling homogéneo ou heterogéneo. Enquanto que no primeiro caso toda a fibra ganha volume uniformemente e não há dissolução, no segundo caso o que acontece mais frequentemente é o fenómeno de ballooning em que o intumescimento ocorre em algumas regiões ao longo das fibras dando origem à formação de balões (Figura 6).
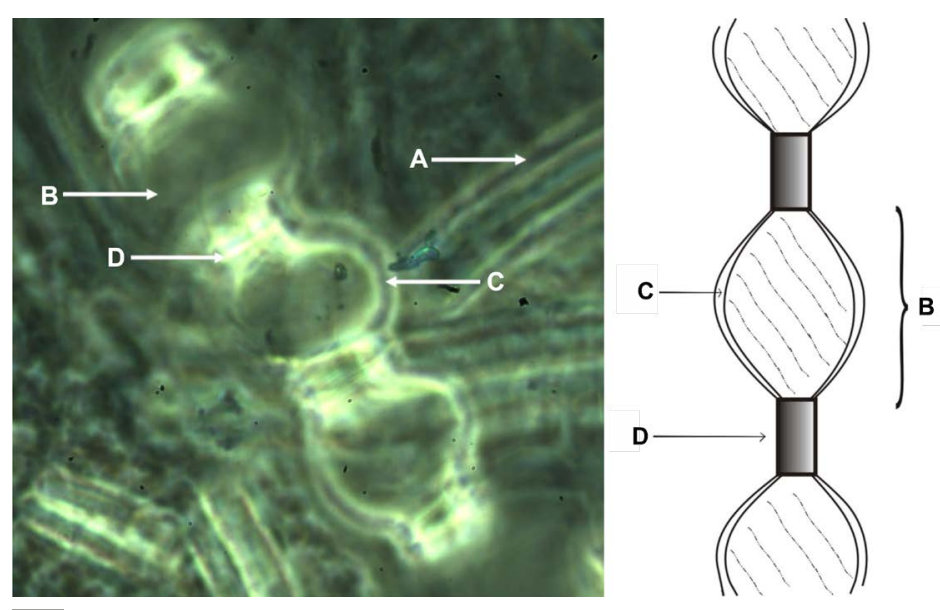

Figura 6 - Fibras intumescidas de celulose nativa.

O ballooning pode ser explicado pelo facto do intumescimento da celulose presente na parede celular secundária causar a extensão e rompimento da parede celular primária. De acordo com esta perspetiva, a celulose "inchada" expande-se pelos rasgos da parede primária que se enrola de modo a formar colares, anéis ou espirais, restringindo a expansão uniforme da fibra e originando os balões. Esta explicação assume que a celulose está num estado de swelling em cada um dos balões. Na Figura 6 pode observar-se uma fibra em fase de ballooning, em que se distinguem por microscopia ótica, e esquematicamente, as diferentes zonas de fibras intumescidas de celulose nativa. A cada uma das zonas desta figura é atribuída uma designação e uma interpretação correspondente. À secção A corresponde parte de uma fibra não intumescida ou uma fibra inteira que ainda não iniciou o processo de swelling mas que pode vir a iniciar mais tarde. Nas regiões da fibra em que o swelling já iniciou podem distinguir-se três secções: o balão (B), composto por celulose intumescida ou mesmo dissolvida, que está dentro da membrana ou parede do balão (C) e a secção não intumescida (D), situada entre dois balões.

0 fenómeno de ballooning permite que o solvente penetre não só nas zonas mais amorfas das fibras, mas também nas mais cristalinas, fazendo com que, em situações ideais, os balões continuem a expandir até rebentarem. Ao rebentar a parede celular primária das fibras, os colares ou anéis formados no ballooning começam a desvanecer-se, dá-se a fragimentação das cadeias de celulose e a sua desintegração, o que resulta na completa dissolução do polímero de celulose.

\section{Características gerais da pasta solúvel para Lyocell}

A pasta solúvel utilizada para a produção de fibras Lyocell deve possuir determinadas características que Ihe permitam um bom desempenho na fase de extrusão dos filamentos, assim como uma qualidade e purificação adequadas no produto final. Deste modo, parâmetros como grau de brancura, índice de viscosidade limite, resistência alcalina, teores de $\alpha$-celulose e pentosanas (hemiceluloses), índice Kappa (indicativo da extensão de deslenhificação da pasta), teores de cinzas, cálcio (e outros metais), materiais inorgânicos e extratáveis, e número de cobre (indicativo da presença de grupos carbonilo na pasta), entre outros, devem ser estudados com vista à produção de uma pasta conforme os requisitos necessários.

Tendo em consideração os parâmetros acima referidos, pode dizer-se que uma pasta solúvel para produção de Lyocell deve ser caracterizada conforme se descreve de seguida. 0 seu grau de brancura deve ser elevado de forma a garantir o brilho e aspeto estético pretendidos em produtos Lyocell, mas também uma boa processabilidade da pasta. 0 índice de viscosidade limite da pasta, e consequentemente o grau de polimerização médio (DP) da celulose, é um dos parâmetros de maior relevância neste setor industrial, uma vez que a dissolução de uma grande parte das fibras de celulose começa pelas extremidades das cadeias. Desta forma, quanto menor o comprimento das cadeias de celulose, maior a probabilidade de uma dissolução mais eficaz e completa. Este parâmetro deve possuir valores inferiores aos correspondentes para a produção de viscose, sendo sempre necessário ter em mente a relação entre a viscosidade da pasta e o processo produtivo em questão. Os valores de resistências alcalinas desta pasta, especificamente a $10 \%$ e a $18 \%$ de hidróxido de sódio, devem ser elevados, indicando uma composição de celulose isenta de frações 
de celulose degradadas e hemiceluloses, assim como o teor de $\alpha$-celulose - quanto mais elevado for, maior grau de pureza terá a pasta. 0 teor de pentosanas deste tipo de pasta não tem necessariamente de ser muito baixo, como o tem de ser para a produção de viscose, por várias razões, muitas delas ainda em estudo. 0 índice Kappa desta pasta deve ser bastante diminuto de forma a representar a presença de uma ínfima quantidade de lenhina (elemento cromóforo e de coesão intercelular). 0 conteúdo da pasta solúvel para Lyocell no que concerne aos seus componentes minoritários, como as cinzas, os metais, os materiais inorgânicos e os extratáveis, deve apresentar resultados muitíssimo reduzidos, indicando uma pasta bem purificada e resultando na inexistência de interferências no processo de regeneração da celulose. Também o valor do número de cobre deste tipo de pasta deve ser baixo, podendo de outra forma originar uma maior propensão para degradação e amarelecimento dos materiais finais [1].

\section{Fibras de celulose em dissolução}

Após tentativas de dissolução laboratorial de uma pasta solúvel (produção especial da Caima) em sistema aquoso de NMO, e recolhidas algumas amostras durante esse procedimento, observou-se e analisou-se o resultado obtido num microscópio ótico Olympus BX41, utilizando uma lente objetiva com ampliação de 40x e o filtro Ph2 correspondente. Na Figura 7, observam-se fibras de celulose em fragmentação. Este tipo de comportamento ocorre quando as fibras entram em contacto com um bom solvente e se quebram, dando origem a pequenos fragmentos que se dissolverão em pouco tempo.

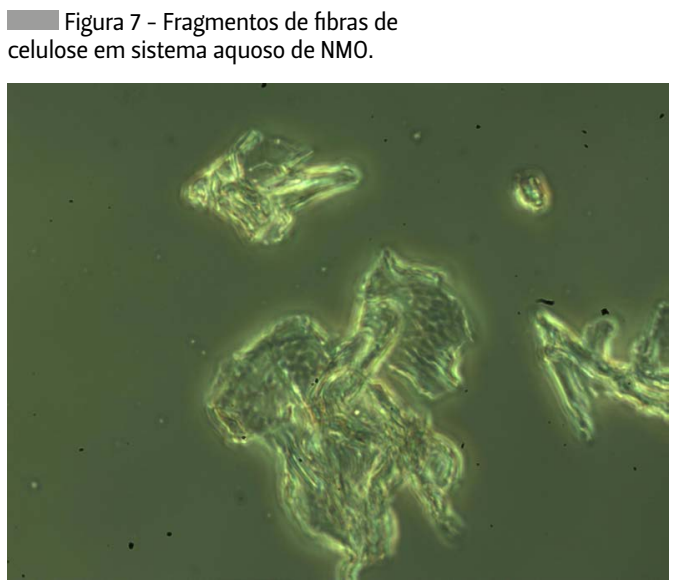

Esta quebra das fibras em fragmentos longitudinais, mais compridos que largos, expressa o facto de haver na parede celular secundária longas zonas amorfas ligadas entre si (nas quais o solvente vai rapidamente dissolver as cadeias celulósicas) e/ou espaços vazios que se estendem ao longo da fibra (onde o solvente vai penetrar por capilaridade).

Quando a dissolução da celulose acontece através do fenómeno de ballooning no processo de swelling heterogéneo, a fibra começa por inchar de forma não homogénea (Figura 8) e irá dissolver-se em quatro passos sucessivos - crescimento dos balões, rebentamento dos balões, dissolução das secções não intumescidas e dissolução das membranas destas secções e das dos balões.

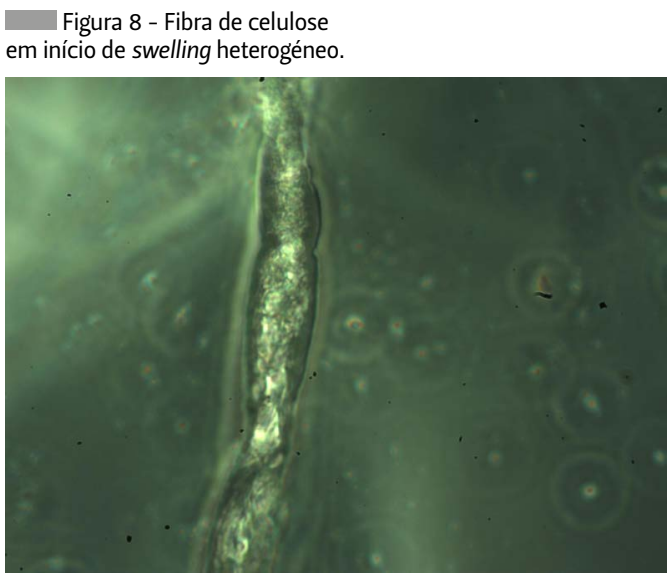

A Figura 9 ilustra um exemplo de uma fibra em que, além de partes de fibra por dissolver, se identifica perfeitamente um balão já formado e em crescimento (I) e mais abaixo um balão em formação que não tem ainda a membrana bem definida (II). Mas, apesar da formação de balões ser um indício de possível dissolução, não fornece uma indicação definitiva de que as fibras de celulose se irão dissolver completamente. Já o rebentamento de balões e a dissolução de secções não intumescidas são indícios mais fortes de que as fibras desta pasta solúvel podem ser dissolvidas em sistema aquoso de NMO para a produção de Lyocell.




Como foi possível verificar na Figura 9, os balões não se formam em simultâneo ao longo da fibra e as secções não intumescidas mantêm o tamanho e aspeto ótico originais da fibra inicial enquanto os balões crescem. 0 diâmetro dos balões cresce (controlado pelo solvente e pelo grau de resistência da membrana), atinge o seu máximo, permanece nesse estado durante algum tempo e, finalmente, os balões rebentam. No rebentamento dos balões, as membranas quebram no ponto de extensão máximo e o que se observa são as membranas mais desvanecidas e as secções não intumescidas mais nítidas. Esta etapa, que também não acontece simultaneamente para todos os balões de uma determinada fibra, pode ser visualizada nas Figuras 10 e 11.

Na Figura 10, observa-se a extremidade de uma fibra de celulose, na qual está a ocorrer o fenómeno de ballooning, e em que se identificam claramente partes de fibra não dissolvida, um balão formado e uma região de um balão rebentado.

Na Figura 11, pode observar-se uma cadeia com espaços onde terão existido balões já rebentados e são visíveis secções não intumescidas ligadas entre si em vias de dissolução. De facto, nas regiões indicadas pelas setas brancas na imagem, identificam-se fios de parede celular a separarem-se dessas secções indiciando o processo de dissolução.

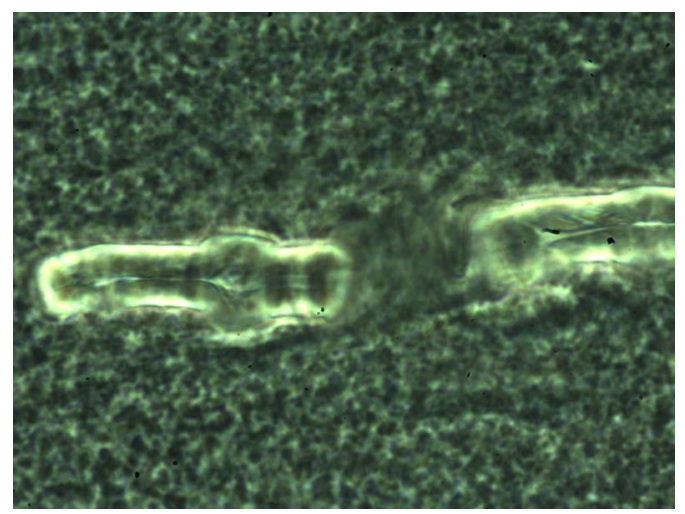

Figura 10 - Extremidade de uma fibra de celulose com rebentamento de balão.

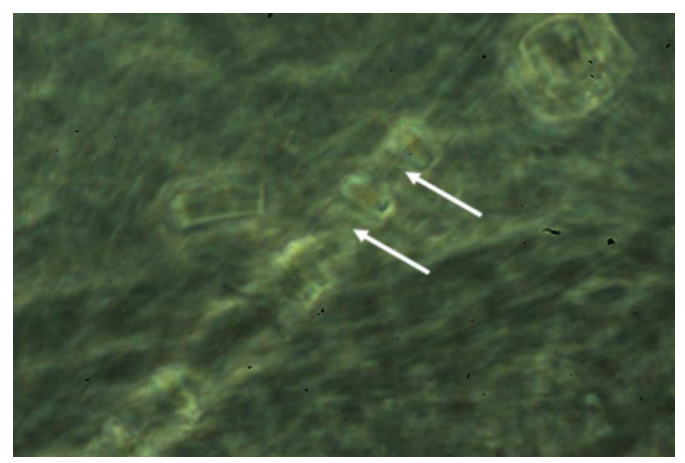

Figura 11 - Fibra de celulose que evidencia rebentamento de balões.

\section{Caracterização por microscopia eletrónica de varrimento (MEV)}

Para a caracterização morfológica das fibras obtidas pelo processo descrito anteriormente, utilizou-se um equipamento localizado no MicroLab, Universidade de Lisboa, denominado Analytical FEG-SEM, JEOL $7001 \mathrm{~F}$ e obtiveram-se as imagens apresentadas na Figura 12, com diferentes ampliações. Nas imagens A a C, identificam-se fibras Lyocell provenientes da pasta da Caima perfeitamente orientadas e com cortes. A imagem $\mathbf{D}$ refere-se a uma ampliação de uma zona da imagem $\mathbf{C}$ e evidencia claramente o efeito "ramalhete" com bastonetes constituídos por fibras curtas e bem orientadas. Esta análise prevê com grande possibilidade a produção de fibras Lyocell com pasta solúvel produzida em Portugal, pela Caima.
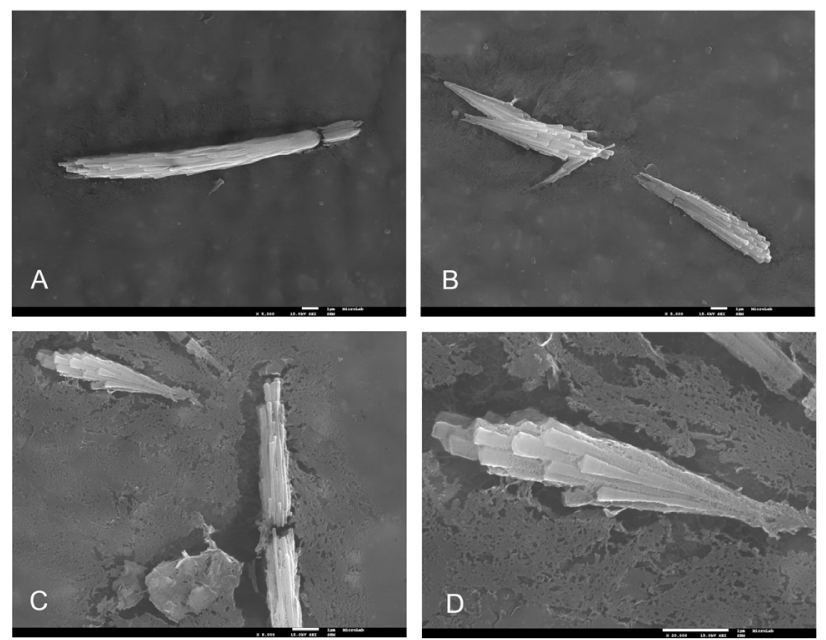

Figura 12 - Imagens de MEV de fibras Lyocell obtidas com a pasta solúvel da Caima, S.A. (A e B - $\mathbf{X}$ 5,000; C - x 8,000; D - x 20,000).

\section{A capacidade nacional para a produção de Lyocell}

Conclui-se com este trabalho que a pasta celulósica solúvel produzida pela Caima - Indústria de Celulose S.A. tem bom potencial para a produção de fibras de celulose regenerada de Lyocell. Portugal tem temperaturas ambientais amenas durante quase todo o ano. A prática de exercício físico está cada vez mais generalizada e a utilização deste material em vestuário desportivo tem vantagens no tratamento e na lavagem destas roupas. É de prever que a comercialização de vestuário com esta composição terá sucesso no nosso país. Também será de equacionar as vantagens no reprocessamento de materiais $100 \%$ Lyocell como resposta ao ciclo global de sustentabilidade, ou seja, desde a matéria-prima ao produto final e à sua biodegradabilidade. Será de fomentar a produção destas fibras em ambientes especiais, vestuário de conforto ou até mesmo como auxiliar de tratamentos médicos onde a pele exige 
cuidados especiais. É ainda de destacar a existência e a garantia de um ciclo global de sustentabilidade graças à possibilidade de reutilização do Lyocell e reforçar a implementação da Agenda 2030 nos Objetivos de Desenvolvimento Sustentável, nomeadamente na convicção da necessidade de se proteger o planeta da sua degradação acelerada, através de padrões ponderados de produção e de consumo, numa indústria moderna e inovadora, empreendedora, da gestão equilibrada dos recursos naturais atendendo às necessidades das gerações presentes e futuras.

\section{Agradecimentos}

A realização deste trabalho não teria sido possível sem a colaboração da Caima - Indústria de Celulose, S.A., nomeadamente da Dr. ${ }^{a}$ Raquel Almeida.

Agradecemos à Fundação para a Ciência e a Tecnologia, Portugal, ao abrigo do projeto UIDB/00100/2020, pelo apoio financeiro à Unidade de Investigação Centro de Química Estrutural.

\section{Notas}

' A grande maioria do trabalho que aqui se apresenta resulta da parte experimental da Unidade Curricular Dissertação do Plano de Estudos do Mestrado em Química Tecnológica, que foi realizada entre 2019 e 2020 na empresa Caima - Indústria de Celulose, S.A., em Constância [1].

\section{Referências}

[1] A. M. Antunes,"Avaliação da pasta solúvel da Caima para produção de fibras Lyocell", Dissertação de Mestrado em Química Tecnológica, sob sigilo até dezembro de 2023, Faculdade de Ciências da Universidade de Lisboa, 2020.

[2] Altri, "Relatório Anual Gestão e Contas 2019", altri.pt/ /media/Files/A/ Altri-V2/reports-and-presentations/reports/portuguese/2019/Altri_ AGM_2019_PT_FHD.pdf (acedido em 18/03/2021).

[3] "O processo produtivo da pasta - Caima", caima.pt/pt/negocio/pastasoluvel (acedido em 18/03/2021).

[4] H. Sixta, Cellulose Chemistry - Lyocell Fibers, 2016. mycourses.aalto.fi/ pluginfile.php/243898/mod_resource/content/1/Lyocell fibers_ June 2016.pdf (acedido em 18/03/2021).

[5] K. Fletcher, Sustainable Fashion and Textiles: Design Journeys, $2^{\text {nd }}$ Ed., Routledge, 2014.

\section{$>$}

\section{*Ana Marta Antunes}

CQE - Centro de Química Estrutural, Faculdade de Ciências, Universidade de Lisboa. É Licenciada e Mestre em Química Tecnológica por CIÊNCIAS ULisboa. A sua experiência alargada inclui Investigação e Desenvolvimento em Química Inorgânica assim como responsabilidades laboratoriais nos setores da Construção e Renovação, Qualidade e Ambiente. Foi administrativa/gestora numa indústria de vidro e dedica-se atualmente à área da Tradução e Revisão em diversas línguas. anamarta.rantunes@gmail.com CIÊNCIA ID: AB12-7097-6B21

\section{$>$}

\section{Maria José Lourenço}

CQE - Centro de Química Estrutural, Faculdade de Ciências, Universidade de Lisboa. Departamento de Química e Bioquímica, Faculdade de Ciências, Universidade de Lisboa.

É Professora Auxiliar no DQB de CIÊNCIAS ULisboa. É membro integrado do Centro de Química Estrutural e pertence ao grupo Termofísica Molecular e Engenharia de Fluidos. Em setembro de 2005 foi distinguida com o Netzsch Young Scientist Award. É autora da patente europeia EP 3 228192 A2 com a empresa alemã BASF. Atualmente é a Coordenadora do $2{ }^{\circ}$ ciclo da Unidade Funcional de Ensino em Química Tecnológica de CIÊNCIAS ULisboa.
$>$

mjlourenco@ciencias.ulisboa.pt ORCID.org/0000-0002-5668-2114

\section{$>$}

Mihaela Postoronca dos Santos

Caima - Indústria de Celulose, S.A.

É Mestre em Engenharia Química pela Universidade de Aveiro. Atualmente exerce funções no Laboratório de Controlo de Qualidade da Caima - Indústria de Celulose, S.A. e integra a equipa de Investigação, Desenvolvimento e Inovação (IDI) do grupo Altri, na área das fibras alternativas e da economia circular. mpostoronca@altri.pt CIÊNCIA ID: 2911-B70D-E919

\section{Samuel Filipe Peres}

Caima - Indústria de Celulose, S.A.

É Mestre em Engenharia Química pela Universidade de Aveiro. Atualmente é o responsável do Laboratório de Controlo de Qualidade da Caima - Indústria de Celulose, S.A. Integra a equipa de Investigação, Desenvolvimento e Inovação (IDI) do grupo Altri nas áreas das fibras alternativas e da economia circular. Exerce igualmente funções no âmbito da certificação de qualidade, ambiente e energia, segurança e saúde no trabalho. speres@altri.pt CIÊNCIA ID: 501B-A290-3F2D 